\title{
Impact of using Internet in leisure time on social isolation of middle school students in Dakahlia \\ Governorate
}

${ }^{1}$ Ass.Prof/ Mohamed El Sayed El Sayed Matar

${ }^{2}$ Ass.Prof/ Hazem Mohammed Yousef Mansour Research Summary

The researchers used the study to identify the effect of using the internet in leisure time on the social isolation of students in the preparatory stage in Dakahlia Governorate. The researchers used the descriptive approach. The internet usage scale was applied in leisure time and the social isolation measure was designed by the researchers to collect the data. The study was conducted on a sample of (873) students in the preparatory phase in Dakahlia governorate for the basic sample and (50) for the survey sample. The most important results were the awareness and awareness of the students to use the Internet in leisure time. The social networking sites (Facebook, Twitter, Watts App) Internet use in most students, there is a positive impact of the dimensions of the use of the
Internet in leisure time on the social isolation of students.

\section{Research Introduction}

The development of scientific-technological characteristic of this era, which exceeded the various Humanities fields led to the phenomenon of free time in the lives of individuals and communities requires standing and need search and examination and monitoring of variables and their problems and their impact on both individuals and communities.

Samanoudi, societies became aware of advanced and States the importance of leisure time increased as a result of scientific and technical progress and proper use this time became one of the aims of modern education and the value should not be underestimated or ignored because one of the main

${ }^{1}$ Assistant professor at Sports Recreation Department, Physical Education Faculty, Mansoura University.

${ }^{2}$ Assistant professor at Sports Recreation Department, Physical Education Faculty, Mansoura University. 
problems currently how human goes and uses his spare time. (Samanoudi:2014)

And I've seen leisure activities evolved dramatically lately especially with openness and technical and technological evolution with new styles and many different methods of traditional activities in leisure and the use of the Internet and attracts large numbers of pupils so For them actively acquire most of their free time thanks to its numerous and diverse qualities.

Qawasmiyeh tenderness suggests, that the Internet made a huge difference in relationships and communication between individuals using the Internet big time is allocated to the virtual world at the expense of family communication and interaction with friends which leads to a sort of schizophrenia and weak skills. Social networking leading to the emergence of numerous social problems. (Qawasmiyeh: 2016).

So in light of the current study problem crystallized massive proliferation and rapid use of the Internet, which has become a real phenomenon in
Egyptian society is almost used home or residential district and in front of the children and their insistence on the availability of this service manages most parents respond to satisfy desire Their children, adding that the Internet is becoming a new and friendly entertainment and leisure which led to a lot of eagerness and interest of students using the Internet at leisure hours and repeatedly which astonished him most parents so often engaged other Using the Internet for rates and hours of time and exaggerated manner which may represent a risk to the lives of most pupils may cause some behavioral or psychological or social risks, as well as relations between individuals, may be affected as a result of poor social interaction and low social networking with friends and colleagues.

So there is a problem threatening the lives of many Egyptian families and society, where there is an increasing use by pupils in junior on this new technology in most of their free time. It has become necessary to study this phenomenon, including the 
pros and cons so that we can take advantage in raising leisure, as well as the scarcity of research on using the internet in your spare time and some social impacts in this age bracket, prompting researchers to study the impact of using the internet in your spare time on the social isolation of pupils in Dakahlia governorate.

\section{The importance of research} and the need for it:

Research importance is highlighted in the following points:

1. Draw the attention of parents and educate them about using their children to the internet and the impact this has on the educational and social dimension.

2. Assist in providing recreational activities aimed at the exploitation of leisure and social sense to the development of this age bracket.

3. An aid in planning the preparation of young people by emphasizing the importance of effective social participation and their role in building society.

4. Assist officials and educators to detect the seriousness of the problem of social exclusion among children and adolescents and to know their causes in order to put some appropriate solutions through the leisure farming to reduce social and psychological and behavioral effects.

\section{Research Purpose:}

This Research aims to the impact of using the internet in spare time on the social isolation of pupils in Dakahlia governorate by answering the following questions:

1. what level of the internet used in leisure time for pupils in Dakahlia governorate?

2. what level of social isolation for pupils in Dakahlia governorate?

3. what is the possibility of predicting of social isolation in terms of Internet use in leisure time for pupils in Dakahlia governorate?

4. are there any statistically significant differences in Internet use in leisure and social isolation due to (type, places of employment, employment level, the employment rate)?

\section{Research procedures:}

The researchers used descriptive approach- survey method due to its relevance to research nature. 
Research Community and Sample:

The research community is in pupils in Dakahlia governorate. The authors chose to arbitrarily search and the sample consisted of (873) of pupils in Dakahlia governorate for the core sample (50) for exploratory sample and from outside the basic sample.

\section{Data collection tool:}

A measure of internet use in free time consists of (50) distributed (4) dimensionsprepared by the researchers. And the social isolation of pupils consists of (35) distributed (5) dimensionsprepared by the researchers.

Steps to design a measure of internet use in leisure and social isolation of pupils in Dakahlia Governorate

Through theoretical readings and reference studies and survey number (9) experts in psychology and recreation facility that (a) the researchers prepared a measure of Internet use in leisure and social isolation of pupils and contained a measure using the Internet in your spare time (4) dimensions: The concept of Internet use, Internet use motives, cons of Internet use, the most widely used Internet services. And social isolation measure contains dimensions: loneliness, empathy, social relationships, self-confidence, anxiety, and stress.

The initial image has displayed the scales proposed for experts to ensure the appropriate dimensions, and (4) dimensions to measure Internet use (b) and (4) dimensions to measure social exclusion (c).

In light of the expert's consent on the scale using the Internet in your spare time (58) and the vocabulary of each dimension after being excluded for one (1) in the first dimension, number (1) in the second dimension, number (1) in the third dimension, and that no such vocabulary $(75 \%)$ Of expert opinions, bringing the scale consists of (55) truly have been made internal consistency, omitted a number (5) of the scale (1) in the first dimension, (2) alone in the second dimension, number (1) in the third dimension, number (1) in the fourth dimension, bringing the number of cubits in the vocabulary. Finalized (50) distributed (4) dimensions of 
the concept of using the Internet (13), Internet use motives (14), cons using the Internet (12), the most widely used Internet services (11), (d).

In light of the expert's consent to remove scale social isolation (43) and the vocabulary of each dimension after being excluded for two (2) alone in the second dimension, and (2) alone in the fourth dimension, number (1) in the fifth dimension, and that no such vocabulary $(75 \%)$ Of expert opinions, bringing the scale consists of (38) truly have been made internal consistency, omitted a number (3) of the scale (1) in the first dimension, and one (1) alone in the third dimension, number (1) in the fifth dimension, bringing the number of the finalization of the standard vocabulary (35) single-Mo Trend (5) dimensions and their loneliness (7), empathy (6), social relations (7), selfconfidence (7), anxiety and stress (8) (e).

The degree is selected for each dimension separately from dimensions and determine the degree College in accordance with a scale (Yes $=$ 3 degrees - somewhat $=2-$ No
= 1 degree), and then calculate the total degree of the scale.

\section{Field study:}

After checking for validity and reliability researchers have applied a measure of Internet use in leisure and social isolation measure on the study sample and core strength (873) for pupils in Dakahlia governorate from $(10 / 2 / 2018 \mathrm{~m})$ to (31/3/2018) After completing the application scales the data was dumped in preparation for appropriate statistical processors.

\section{Results' Presentation and} Discussion:

1. Frequency and percentages to the concept of using the Internet in your spare time for pupils.

It is clear from table (9), the realization of pupils enrolled to the concept of using the Internet as (interactive tool can be used at any time and any place) from the top of the vocabulary $(86.025 \%)$, and returns That the Internet is becoming a modern and interactive communication means and increasingly use them one day after another. This is consistent with the study of (Salah, 2016), which 
most students grasp the concept of the Internet in their readiness and permanent interest in thinking about it.

2. Frequency and percentages of Internet use motives in spare time for pupils.

It is clear from table (10), arrange the motives of using Internet in spare time came the motive (use the Internet because its many recreational games) of the major motives that most students seeking to achieve (85. 223\%), due to the attention of most pupils to exercise some recreational electronic games where it's one of my favorite tools and lovely for leisure. This is consistent with the study of starboard (Magdi, 2017), which most students achieving their supplies tendency of using the Internet.

3. Frequency and percentages of cons using the Internet in spare time for pupils.

It is clear from table (11), perceiving the pupils to use Internet cons where single came (family complains to escape using the Internet for a long time) of the highest negatives $(77.663 \%)$, This is due to the desire of most students and their interest in leisure and also search for fun and entertaining activities. This is consistent with the study of (Malakeh. 2017), the cons of Internet use and personal problems caused as a result of preoccupation for long times.

4. Frequency and percentages for the most widely used Internet services in free time for pupils.

It is clear from table (12), perceiving the pupils study sample of services available in the Internet as a service (social networking sites (Facebook, Twitter, TS August) of top services used $(84.76 \%)$, due to the desire of most pupils to make new friends and meet new people from around the world. This is consistent with the study of starboard (Magdi, 2017), which emphasizes the realization of most students and their interest in using several services available on the Internet.

5. Frequency and percentages of the axis of loneliness for pupils.

It is clear from table (13), the highest percentage of came alone (tend to be alone most of the time) and made by 
(81.29\%), due to the preference of many pupils spend most leisure use Or the Internet and continuously leading to poor communication with family members, this is consistent with the study of (Malakeh. 2017), which indicated that most students suffer from symptoms of psychological loneliness mostly affecting poor direct contact with others.

\section{Frequency and} percentages to focus empathy (emotional) of pupils

It is clear from table (14), the highest percentage of came alone (I find that others feel weird when you say honestly about my feelings and my emotions) (79.76\%), due to the presence of certain behaviors and attitudes Of Internet users which may conflict with some customs and behaviors and community traditions. This is consistent with the study of (Shim, 2007), which indicates that the Internet some negative effects including low emotional involvement, social and emotional withdrawal.

7. Frequency and percentages of the axis of social relations of pupils
It is clear from the table (15), the highest percentage of came alone (I am ashamed when social relations with others) by $(82.21 \%)$, due to most of the pupil's attention of Internet users in relationships Some social networking sites new friends and escape direct confrontation. This is consistent with the study of (Riad, 2009), indicating the presence of some negative effects of Internet use in the psychological field.

8. Frequency and percentages to axis selfconfidence to pupils

It is clear from the table (16), the highest percentage of came alone (I find it hard to decide myself) (77.28\%), due to the intervention of some parents in their children's lives at this stage and defines the scientific attitudes or Profile. This is consistent with the study of (Malakeh. 2017), which indicate a decline in confidence among some pupils at this stage.

9. Frequency and percentages of the axis of anxiety and stress for pupils

It is clear from the table (17) was the highest percentage of single (I am concerned when 
I think of my career in school) (77.66\%), mainly because there is some psychological pressure by parents and family on most pupils achieve High rates of success and excellence. This is consistent with the study of
(Shim, 2007), that indicates a relationship between average hours of Internet use and anxiety and stress.

10. the impact of using the Internet in your spare time on social exclusion of pupils

\begin{tabular}{|c|c|c|c|c|c|c|c|}
\hline $\begin{array}{l}\text { Independent } \\
\text { variables }\end{array}$ & $\begin{array}{l}\text { Dependent } \\
\text { variable }\end{array}$ & $\mathbf{R}$ & $\mathbf{R 2}$ & B & $\begin{array}{c}\text { Value } \\
\text { of } \beta\end{array}$ & $\begin{array}{c}\begin{array}{c}\text { Value } \\
\text { of } \mathbf{T}\end{array} \\
\end{array}$ & $\begin{array}{c}\text { Level } \\
\text { indication }\end{array}$ \\
\hline $\begin{array}{l}\text { The concept } \\
\text { of using the } \\
\text { Internet }\end{array}$ & \multirow{5}{*}{$\begin{array}{l}\text { Social } \\
\text { isolation } \\
\text { measure } \\
\text { for pupils }\end{array}$} & $.367 *$ & 0.135 & 2.772 & & $14.740 *$ & .000 \\
\hline $\begin{array}{ll}\text { Motives for } \\
\text { using } \\
\text { Internet }\end{array}$ & & $.307 *$ & 0.094 & $1 . \overline{279}$ & -.632 & $2.539 *$ & .011 \\
\hline $\begin{array}{l}\text { Cons of using } \\
\text { the Internet }\end{array}$ & & $.482 *$ & 0.232 & $\begin{array}{c}- \\
1.348\end{array}$ & -.575 & $2.645^{*}$ & .008 \\
\hline $\begin{array}{l}\text { The most widely } \\
\text { used Internet } \\
\text { services }\end{array}$ & & $.352 *$ & 0.124 & $\begin{array}{c}- \\
1.109 \\
\end{array}$ & -.598 & $2.188 *$ & .029 \\
\hline $\begin{array}{l}\text { College class } \\
\text { of Internet } \\
\text { usage meter } \\
\text { in free time }\end{array}$ & & $.468 *$ & 0.219 & $1 . \overline{402}$ & -.414 & $2.708^{*}$ & .007 \\
\hline Value of F & $8.034 *$ & $\begin{array}{c}\text { Level } \\
\text { indication }\end{array}$ & & & & & \\
\hline
\end{tabular}

The value of " $r$ " is significant at 0.05

Illustrated by the table

(19) the moral model, as verified there is a positive correlation between Internet use in leisure and social isolation of pupils, due to the attention of most students to use the Internet in your spare time and that its characteristics and advantages Magnet. This is consistent with the study of (cream, 2006), a positive relationship and therefore social decline and reduced quality of life among some pupils in this age.

11. Significant differences in Internet use in leisure time for pupils due to type (malefemale)

Illustrated by table (20) that there were no statistically significant differences in Internet usage meter in spare 
time of pupils according to the variable type as the value (v) indexed value of the abstract level (0.05), this may be because the Internet is one of the activities that define $p$ Interest to all users of the sexes $(\mathrm{m}-\mathrm{f})$ at this stage this is consistent with the study of starboard (Magdi, 2017), which refers to the lack of statistically significant differences in Internet usage according to the variable type.

\section{Significant differences} in Internet use in leisure time for pupils due to places of use (indoors - outdoors)

Illustrated by table (22) that there were statistically significant differences in college class to measure Internet use in leisure time for pupils According to the variable usage for places inside the House where the value (v) indexed value calculated more abstract level (0.05), due to the availability of Internet connection inside the home through Wi-Fi or through Internet cards available on mobile networks.

13. An indication of the differences in the use of the Internet in your spare time and attributed usage level

\section{(less than an hour - more than an hour)}

Illustrated by table (24) that there were no statistically significant differences in Internet usage meter in spare time of pupils according to variable usage level where the value of $(\mathrm{V})$ the indexed value of the abstract level (0.05), this may be due to students awareness and knowledge of the use of the Internet is one of the most important techniques that allow them to accomplish their tasks and requirements. This is consistent with the study of (Malakeh. 2017), which most students grasp the concept of the Internet in their readiness and permanent interest in thinking about it.

\section{Significant differences} in Internet usage at leisure to pupils and attributed the utilization rate

shown in table (26) that there were statistically significant differences in the concept of using the Internet for pupils in accordance with the employment rate variable for a day where the value (p) Indexed value calculated more abstract level (0.05) and no statistically significant differences in Internet usage 
meter dimensions in spare time of pupils according to the employment rate variable where the value (p) of indexed value abstract level (0.05), may Due to the students ' awareness and knowledge of the use of the Internet is one of the most important techniques that allow them to collect scientific information and knowledge. This is consistent with the study of starboard (Magdi, 2017), which most students grasp the concept of the Internet in their readiness and permanent interest in thinking about it.

\section{Research conclusion:}

- There is awareness of the students to use the Internet in your spare time, where students study the convergence, in General, to understand the concept of the Internet as an integral part of modern life.

- multiple services provided by the Internet among students in middle school in leisure time comes in the introduction to use social networking sites (Facebook, Twitter, TS August), cultural forums, follow newspapers sites.
- a correlation between Internet use in leisure and social isolation of pupils.

- a positive effect for dimensions using the Internet in your spare time on the social isolation of pupils.

Research Recommendations

- The Ministry of education needs to develop a media strategy to educate students and directing them a proper orientation to use the Internet and rationalize the handle so as not to affect the adversely wasted use of leisure time and the loss of value.

- $\quad$ scientific attention needs to study the problems of using the Internet in spare time and negative effects for children and adolescents and that their lives and impact psychological and social services.

- $\quad$ enhancing the role of the family in social and psychological climate and composition of positive trends for their children to practice hobbies and favorite activities at leisure.

- $\quad$ school activity should focus on pupils with their preferences and aptitudes and abilities and teach them skills and hobbies associated with 
leisure and recreation, raise their motivation to practice

References:

1- Haidar Karim (2006): Social isolation among preparatory students, published research, Journal of the Faculty of Basic Education, Mustansiriya University.

2- Hanan Qawasmiyeh (2016): Social networking sites and their role in increasing the social isolation of Algerian university students (a field study for a sample of the students of the Department of Human Sciences Facebook model), Master Thesis, Faculty of Humanities and Social Sciences, Arabi University, Tabs, P.P51.

3- Malakeh,M (2017): Prevalence of Internet and associated risk factors in Jordanian School Students, Computers in Human Behavior Journal Issn07475632, p556563.

4- Mohamed Samanoudi, And others (2014): Entrance
Sports Recreation, Mansoura, Library tree Alder, P.P11.

5- Riad Al Asmi (2009): The sense of psychological loneliness and its relation to depression, isolation and social support, published research, Journal of the Union of Arab Universities for Education and Psychology, Volume VII, No. 2.

6- Salah Mohammed (2016): Adolescents' use of online scouting sites and their expectations, Master Thesis, Graduate Institute of Childhood, Ain Shams University.

7- Shim, y (2007): Impact of the Internet on Teenagers Face to Face Communication, Global Media Journal, V6(1).

8- Yemeni Magdy (2017): The motives of adolescents' use of serial images (comics) on the internet and the resulting impressions, Master Thesis, Institute of Graduate Studies for Children, Ain Shams University. 